\title{
Effect of Moderate Alcohol Consumption on Parameters of Reverse Cholesterol Transport in Postmenopausal Women
}

Aafje Sierksma, Susanne H. F. Vermunt, Inge M. Lankhuizen, Martijn S. van der Gaag,† Leo M. Scheek, Diederick E. Grobbee, Arie van Tol, and Henk F. J. Hendriks

\begin{abstract}
Background: Alcohol consumption is associated with increased high-density lipoprotein (HDL) cholesterol levels. One of the main antiatherogenic functions of HDL is reverse cholesterol transport. Three early steps of reverse cholesterol transport are (1) cellular cholesterol efflux, (2) plasma cholesterol esterification (EST), and (3) cholesteryl ester transfer (CET) to apolipoprotein B-containing lipoproteins. Our previous study in healthy middle-aged men showed that moderate alcohol consumption increases cellular cholesterol efflux and EST. This study investigated the effect of moderate alcohol consumption on three early steps of reverse cholesterol transport in postmenopausal women.

Methods: In a randomized crossover study, 18 postmenopausal women-all apparently healthy, nonsmoking, and moderate alcohol drinkers-consumed white wine or white grape juice with evening dinner during 2 successive periods of 3 weeks. During the white wine period, alcohol intake equaled $24 \mathrm{~g} / \mathrm{day}$. At the end of each of the two experimental periods, blood samples were collected.

Results: Three weeks of alcohol consumption increased serum HDL cholesterol levels $(5.0 \% ; p<0.05)$, serum HDL phospholipid levels $(5.8 \% ; p<0.05)$, and the ex vivo cellular cholesterol efflux capacity of plasma, measured with Fu5AH cells $(3.4 \% ; p<0.05)$. Plasma EST and CET did not change.

Conclusions: Moderate alcohol intake increases serum HDL cholesterol level and stimulates cellular cholesterol efflux in postmenopausal women. Moderate alcohol consumption does not seem to affect two other early steps of reverse cholesterol transport at this level of alcohol intake. Our data suggest that the relative protection of moderate alcohol consumption against cardiovascular disease in postmenopausal women may involve the stimulation of reverse cholesterol transport through increased HDL.

Key Words: Moderate Alcohol Consumption, Cholesterol Efflux, Cholesterol Esterification, Cholesteryl Ester Transfer, Postmenopausal Women.
\end{abstract}

$\mathbf{M}$ ODERATE ALCOHOL CONSUMPTION is inversely associated with cardiovascular disease (Colditz et al., 1985; Grobbee et al., 1999; Stampfer et al., 1988), and at least $50 \%$ of the protective action of moderate alcohol consumption can be attributed to an increase in high-density lipoprotein (HDL) cholesterol (Castelli et al., 1977; Criqui et al., 1987). Alcohol consumption affects lipoprotein metabolism. It is suggested that moderate

From the Department of Nutritional Physiology, TNO (Netherlands Organisation for Applied Scientific Research) Nutrition and Food Research (AS, SHFV, MSvdG, HFJH), Zeist, The Netherlands; Julius Center for Health Sciences and Primary Care, University Medical Center Utrecht (AS, DEG), Utrecht, The Netherlands; and Department of Biochemistry, Erasmus University Medical Center (IML, LMS, AvT), Rotterdam, The Netherlands.

†Deceased.

Received for publication May 23, 2003; accepted January 7, 2004.

Supported by the Dutch Foundation for Alcohol Research.

Reprint requests: Henk F. J. Hendriks, PhD, TNO Nutrition and Food Research, Department of Nutritional Physiology, P.O. Box 360, 3700 AJ Zeist, The Netherlands; Fax: 31-30-694-4928; E-mail: hendriks@voeding.tno.nl.

Copyright () 2004 by the Research Society on Alcoholism.

DOI: 10.1097/01.ALC.0000122763.30770.F5 drinking increases HDL cholesterol by increasing the transport rates of both apolipoprotein (apo) A-I and apo A-II, the precursors of HDL, without affecting their fractional catabolic rate (De Oliveira E Silva et al., 2000). Triglycerides are transiently increased acutely after moderate alcohol consumption (Hendriks et al., 1998), whereas long-term excessive alcohol use causes chronically increased triglyceride levels.

HDL is able to remove excess cellular cholesterol, with subsequent return of this cholesterol to the liver, in the process of reverse cholesterol transport (Fielding and Fielding, 1995; Rothblat et al., 1999). The removal of free cholesterol from peripheral cells by interactions between HDL and cells (cellular cholesterol efflux) is the first step of reverse cholesterol transport. During the second step of reverse cholesterol transport, cholesterol is esterified by plasma lecithin:cholesterol acyltransferase (LCAT) and incorporated into HDL particles (Glomset, 1968). This is called plasma cholesterol esterification (EST). HDL cholesteryl esters are subsequently transferred to apo B-containing lipoproteins (low-density lipoprotein and very-lowdensity lipoprotein), in exchange for triglycerides, by 
Table 1. Characteristics of the Postmenopausal Women $(n=18)$ Included in the Data Analysis

\begin{tabular}{lcc}
\hline \multicolumn{1}{c}{ Characteristic } & Mean (SD) & Range \\
\hline Age (years) & $57(5)$ & $49-65$ \\
BMI (kg/m ${ }^{2}$ ) & $24.1(2.1)$ & $21.3-27.7$ \\
Hemoglobin (mmol/liter) & $8.7(0.4)$ & $8.1-9.4$ \\
Triglycerides (mmol/liter) & $1.1(0.5)$ & $0.7-2.1$ \\
Total cholesterol (mmol/liter) & $6.6(0.8)$ & $5.0-7.8$ \\
HDL cholesterol (mmol/liter) & $2.0(0.4)$ & $1.0-2.8$ \\
LDL cholesterol (mmol/liter) & $4.2(0.8)$ & $2.5-5.5$ \\
ASAT (units/liter) & $19(4)$ & $15-31$ \\
ALAT (units/liter) & $16(6)$ & $7-33$ \\
GGT (units/liter) & $19(15)$ & $9-72$ \\
Glucose (mmol/liter) & $5.1(0.5)$ & $4.3-6.0$ \\
FSH (IU/liter) & $94(22)$ & $59-142$ \\
Estradiol (pg/ml) & $39(15)$ & $26-63$
\end{tabular}

BMI, body mass index; ASAT, aspartate aminotransferase; ALAT, alanine aminotransferase; GGT, $\gamma$-glutamyltransferase; FSH, follicle-stimulating hormone; LDL, low-density lipoprotein.

cholesteryl ester transfer protein (CETP) (Tall, 1993), a process called cholesteryl ester transfer (CET).

Our previous study in healthy middle-aged men showed that 3 weeks of moderate alcohol consumption, independent of the kind of alcoholic beverage, increased cellular cholesterol efflux and EST (Van der Gaag et al., 2001). The aim of the present study was to examine the effects of moderate alcohol consumption on three early steps of reverse cholesterol transport in healthy postmenopausal women.

\section{METHODS}

Subjects

The study was conducted at TNO Nutrition and Food Research (Zeist, The Netherlands). The study was performed according to the International Conference on Harmonisation of Technical Requirements for Registration of Pharmaceuticals for Human Use Guidelines for Good Clinical Practice, complied with the Declaration of Helsinki, and was approved by the TNO Medical Ethics Committee. Eighteen nonsmoking postmenopausal women were recruited from the pool of volunteers from TNO Nutrition and Food Research and through an advertisement in a local newspaper. The protocol was carefully explained to the volunteers, and their written, informed consent was obtained. Subjects were eligible if they fulfilled the following inclusion criteria: consumption of 21 or fewer alcohol-containing beverages per week, body mass index between 19 and $30 \mathrm{~kg} / \mathrm{m}^{2}$, no family history of alcoholism, aged 75 years or younger, and not taking medication on a regular basis (including hormone-replacement therapy). Subjects were healthy, as indicated by their medical history and physical examination by the medical investigator. Blood concentrations of follicle-stimulating hormone and estradiol were more than $40 \mathrm{IU} /$ liter and less than $70 \mathrm{pg} / \mathrm{ml}$, respectively. All subjects completed the study successfully. Characteristics of the study population are given in Table 1 .

\section{Study Design}

The subjects entered a randomized, crossover trial consisting of two periods of 3 weeks. All subjects consumed either $250 \mathrm{ml}$ of white wine (24 g of alcohol; table wine "du Valbon," $12 \%$ vol alcohol) or $250 \mathrm{ml}$ of white grape juice (Fruitdruifje, Riedel Drankenindustrie, Ede, The Netherlands) daily during the evening dinner at home. One week before the study started and during the study, subjects were not allowed to consume any (additional) alcoholic beverage or grape juice. Both the participants and the staff were unblinded to the treatment sequence. Compliance to the protocol was checked by a daily questionnaire. Energy and nutrient intake during each treatment period were assessed by use of a derivative of a validated food frequency questionnaire (Grootenhuis et al., 1995). Body weight was determined at the end of each treatment period with the subjects wearing indoor clothing, without shoes, wallet, and keys.

\section{Blood Sampling and Analysis}

At the end of each of the two experimental periods, blood samples were collected. Blood was taken from the antecubital vein and collected in an ice-chilled tube containing ethylenediaminetetraacetic acid and in a tube containing gel and clot activator (Vacutainer systems, Becton Dickinson, Plymouth, UK). To obtain plasma, blood was centrifuged for $10 \mathrm{~min}$ at $2000 \times g$ and $4^{\circ} \mathrm{C}$ within $1 \mathrm{hr}$ after collection. To obtain serum, blood was centrifuged for $10 \mathrm{~min}$ at $2000 \times g$ and $4^{\circ} \mathrm{C}$ approximately $25 \mathrm{~min}$ after collection. All aliquots were stored at $-80^{\circ} \mathrm{C}$ until analysis.

HDL was separated from the apo B fraction by precipitation of the latter with polyethylene glycol (Mertz and Thuilot, 1985; Widhalm and Pakosta, 1991) by using a commercially available kit (Quantolip, Immuno Diagnostics, Vienna, Austria). Serum triglycerides, total and HDL cholesterol, and free cholesterol and phospholipids in HDL were analyzed enzymatically (Boehringer, Mannheim, Germany). HDL cholesteryl esters were calculated as the difference between HDL free cholesterol and total HDL cholesterol. The coefficients of variation $(\mathrm{CVs})$ within runs were $0.8 \%$ for total cholesterol, $1.5 \%$ for triglycerides, and $1.3 \%$ for HDL cholesterol. The apo A-I was analyzed in serum by an immunoturbidimetric assay (Tina-quant ${ }^{\circledR}$ kit apo A-I, Boehringer). The $\mathrm{CV}$ within runs was $1.1 \%$.

Plasma cellular cholesterol efflux was measured from Fu5AH cells as described by De La Llera Moya et al. (1994). In short, Fu5AH cells (donated by Dr. Natalie Fournier, Laboratoire de Biochimie, Faculté des Sciences Pharmaceutiques, Châtenay-Malabry, France) were grown to confluency in the presence of $\left[{ }^{3} \mathrm{H}\right]$ cholesterol. After removal of medium containing the labeled cholesterol, the cells were allowed to equilibrate for $24 \mathrm{hr}$. Subsequently, cholesterol efflux was measured in triplicate over $4 \mathrm{hr}$ in the presence of 20 -fold diluted plasma samples. Cellular cholesterol efflux (radiolabel present in the culture medium after $4 \mathrm{hr}$ ) is expressed as a percentage of the radioactivity initially present in the cells (fractional efflux). Data were corrected for blanks, that is, the amount of label in the medium after $4 \mathrm{hr}$ in the absence of plasma. The fractional cholesterol efflux with Fu5AH cells is a measure of the capacity of a specific plasma sample to remove labeled cholesterol via the scavenger receptor class B type I. The within-assay CV of the cholesterol efflux assay was $5.5 \%$.

Plasma EST was measured after the addition of $\left[{ }^{3} \mathrm{H}\right]$ cholesterol to total plasma. After $1 \mathrm{hr}$ of incubation at $37^{\circ} \mathrm{C}$, lipids were extracted, and $\left[{ }^{3} \mathrm{H}\right]$ cholesteryl esters were isolated as described by Dullaart et al. (1999). The reaction is linear with time for at least $3 \mathrm{hr}$. The within-assay CV was $5.4 \%$.

Plasma CET was measured by using endogenous lipoproteins by a modification of the isotopic method of Channon et al. (1990), as described previously (Dullaart et al., 1999). Briefly, plasma was preincubated overnight on ice with a $\left[{ }^{3} \mathrm{H}\right]$ cholesterol-albumin emulsion and subsequently incubated for $3 \mathrm{hr}$ at $37^{\circ} \mathrm{C}$. The appearance of radiolabeled cholesteryl esters in precipitated apo B-containing lipoproteins is a measure for CET. The within-assay CV was $7.1 \%$.

\section{Statistical Methods}

Data were analyzed by using the SAS statistical software package (SAS/STAT version 6.12, SAS Institute, Cary, NC). Treatment effects were assessed by analysis of variance by use of general linear modeling. Two-sided $p$ values were considered statistically significant at $p \leq 0.05$.

\section{RESULTS}

No important deviations in consumption of the supplied beverages occurred during the study. According to the food 
Table 2. Serum Lipids, HDL Lipids, apo A-I Concentration, and Plasma Activities of Three Parameters of Reverse Cholesterol Transport After 3 Weeks' Consumption of White Grape Juice or White Wine

\begin{tabular}{|c|c|c|c|}
\hline Variable & White grape juice & White wine & $p$ Value \\
\hline Triglycerides (mmol/liter) & $1.5(0.6)[1.2-1.8]$ & $1.5(0.6)[1.2-1.8]$ & 0.88 \\
\hline Total cholesterol (mmol/liter) & $6.3(0.8)[5.9-6.6]$ & $6.4(0.8)[6.0-6.8]$ & 0.31 \\
\hline HDL cholesterol (mmol/liter) & $1.79(0.43)[1.57-2.00]$ & $1.88(0.45)[1.65-2.11]$ & 0.02 \\
\hline HDL phospholipids (mmol/liter) & $1.91(0.29)[1.77-2.06]$ & $2.02(0.36)[1.84-2.20]$ & 0.008 \\
\hline HDL cholesteryl esters (mmol/liter) & $1.01(0.38)[0.82-1.21]$ & $1.06(0.45)[0.84-1.28]$ & 0.73 \\
\hline Apo A-I (g/liter) & $1.52(0.19)[1.42-1.62]$ & $1.54(0.23)[1.43-1.66]$ & 0.38 \\
\hline \multicolumn{4}{|l|}{$\begin{array}{c}\text { Three parameters of reverse } \\
\text { cholesterol transport }\end{array}$} \\
\hline Cellular cholesterol efflux (\%) & 36.96 (2.97) [35.49-38.44] & 38.22 (3.86) [36.30-40.14] & 0.046 \\
\hline EST (nmol/ml plasma/hr) & $102.2(22.0)$ [91.2-113.2] & 103.0 (19.5) [93.3-112.7] & 0.78 \\
\hline CET (nmol/ml plasma/hr) & 38.4 (13.3) [31.7-45.0] & 38.9 (11.1) [33.3-44.4] & 0.71 \\
\hline
\end{tabular}

Data are expressed as mean (SD) [confidence interval].

EST, plasma cholesterol esterification; CET, cholesteryl ester transfer.

frequency questionnaire, energy and nutrient intake did not differ between treatment periods. In addition, average body weight did not differ between white wine and white grape juice consumption (data not shown).

In Table 2, serum lipids, HDL lipids, apo A-I concentration, and activities of three parameters of reverse cholesterol transport after 3 weeks of white grape juice and white wine consumption are given. Serum HDL cholesterol and HDL phospholipid levels were increased by 5.0 and 5.8\%, respectively, after white wine consumption compared with white grape juice consumption. Cellular cholesterol efflux increased by $3.4 \%$. White wine consumption did not change plasma EST, serum HDL cholesteryl ester level, or serum apo A-I concentration. Also, CET, another parameter of reverse cholesterol transport, was not affected significantly by white wine consumption.

\section{DISCUSSION}

To our knowledge, this is the first study to examine the effect of moderate alcohol consumption on parameters of reverse cholesterol transport in postmenopausal women. The study showed that a moderate daily dose of alcohol consumed with evening dinner for 3 weeks increased the serum HDL cholesterol level and the capacity of plasma to induce cellular cholesterol efflux. Plasma EST and CET, two other steps of reverse cholesterol transport, were not affected.

Two characteristics of the study need to be addressed. First, moderate alcohol consumption increased serum HDL cholesterol level by $5.0 \%$. In our previous dietcontrolled studies in postmenopausal women, serum HDL cholesterol levels increased by approximately $12 \%$ after 3 weeks of moderate alcohol consumption (Sierksma et al., 2002; Van der Gaag et al., 2000). The reason for this apparent discrepancy may be the lower daily dose of alcohol $(24 \mathrm{~g}$ of ethanol versus $30 \mathrm{~g}$ of ethanol in the previous studies) and the absence of dietary control. A less dramatic HDL cholesterol increase could also explain the smaller, alcohol-induced, increase in cellular cholesterol efflux in this study (3.4\%). In a diet-controlled study in healthy middle-aged men, we showed a $6.2 \%$ increase of cellular cholesterol efflux after 3 weeks of moderate alcohol consumption (Van der Gaag et al., 2001), an increase comparable with other dietary interventions (Blanco-Molina et al., 1998; Sakr et al., 1996). Second, cellular cholesterol efflux was measured by using a model cell, the rat hepatoma cell line Fu5AH. These cells have very high levels of membrane scavenger receptor class B type I and very low levels of another receptor that mediates cellular cholesterol efflux: the adenosine triphosphate cassette binding protein A1 (ABCA1) (Bortnick et al., 2000; Ji et al., 1997). Another approach would have been to measure cholesterol efflux from macrophages, such as the J774 cell line, because macrophages are involved in the initial development of the atherosclerotic plaque (Ross, 1995). In these cells, ABCA1 can be stimulated by cyclic adenosine monophosphate (Bortnick et al., 2000; Oram et al., 2000), thus measuring ABCA1-dependent cellular cholesterol efflux. HDL phospholipids have been reported to be major determinants of the cholesterol efflux measured by Fu5AH cells (Fournier et al., 1997), but also in the ABCA1-facilitated cholesterol efflux. In our study, the relative alcohol-induced increase in serum HDL phospholipid levels indeed correlated with the relative alcohol-induced increase in plasma cellular cholesterol efflux (Pearson $r=0.47 ; p=0.047$ ). The regression equation is as follows (see also Fig. 1):

change in efflux $(\%)=1.4+0.38$

$$
\times \text { change in HDL phospholipids }(\%)
$$

After efflux of cholesterol from cells to plasma, the free cholesterol is esterified by LCAT and incorporated into HDL particles (Fielding and Fielding, 1995). In these postmenopausal women, plasma EST did not change after moderate alcohol consumption. In our previous study in middle-aged men, plasma EST increased by $10.8 \%$ after 3 weeks of moderate alcohol consumption (Van der Gaag et al., 2001). Previously, we reported a tendency for increased EST in the postprandial phase due to red wine consumption with dinner (Van Tol et al., 1995) and increased levels of LCAT activity $9 \mathrm{hr}$ after dinner with red wine or spirits (Hendriks et al., 1998), whereas Nishiwaki et al. (1994) did 


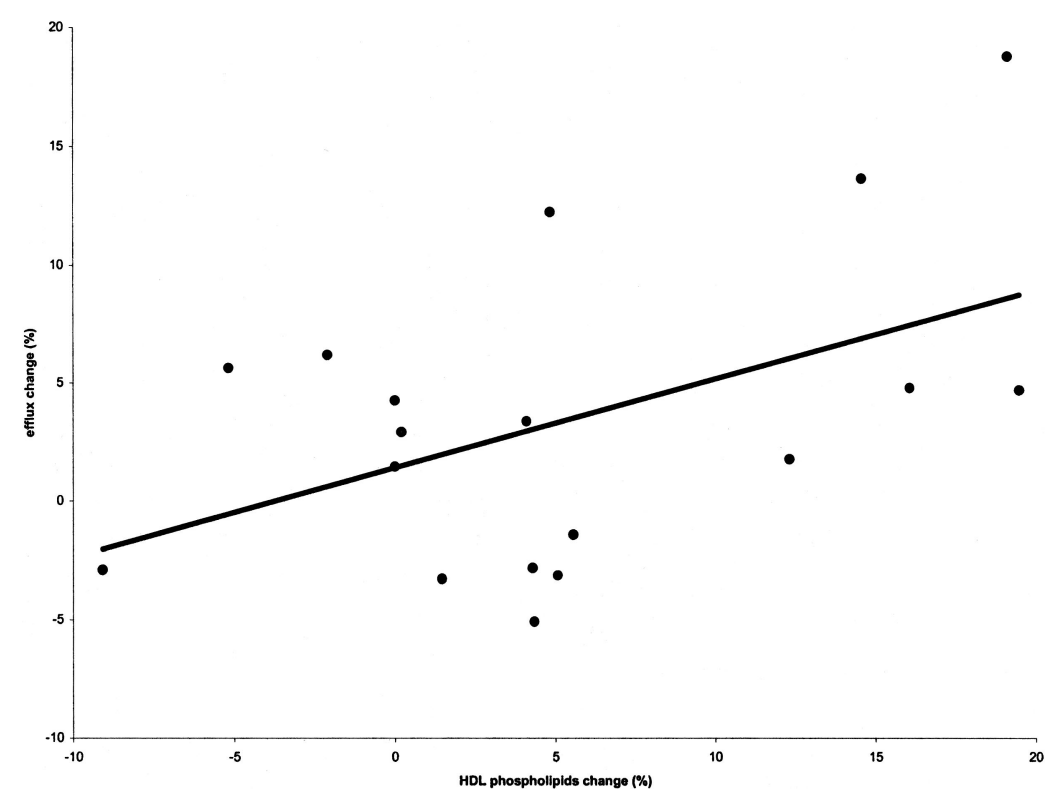

Fig. 1. Relationship between relative alcohol-induced changes in HDL phospholipids and efflux.

not observe an effect of moderate drinking on LCAT activity. Schuler-Lüttmann et al. (2000) reported that apo A-I may determine EST capacity. In the current study, there was indeed a strong correlation between relative alcoholinduced changes in serum apo A-I concentration and plasma EST (Pearson $r=0.70 ; p=0.003$ ).

The cholesteryl esters synthesized by LCAT are transferred to apo B-containing lipoproteins by CETP, a process called CET. Clearance of these apo B lipoproteins by hepatic receptors delivers cell cholesterol to the liver, where it can be degraded and excreted from the body via bile. In the postmenopausal women participating in this study, plasma CET was unchanged after moderate alcohol consumption. This is not surprising, because plasma triglyceride levels (reflecting the concentration of VLDL, the acceptors in CET) are unchanged after alcohol consumption, and in our previous intervention studies (Hendriks et al., 1998; Van Tol et al., 1995) and in studies by others, no effect of alcohol on plasma CETP activity levels was observed (Nishiwaki et al., 1994; Senault et al., 2000). Only in the postprandial phase, when triglyceride-rich lipoproteins are increased, does alcohol seem to increase lipid transfer reactions (Van Tol et al., 1995).

In summary, our findings show that moderate alcohol intake increases serum HDL cholesterol level and stimulates cellular cholesterol efflux in postmenopausal women. Moderate alcohol consumption does not seem to affect two other early steps of reverse cholesterol transport at this level of alcohol intake. Our data suggest that the relative protection of moderate alcohol consumption against cardiovascular disease in postmenopausal women may involve stimulation of reverse cholesterol transport through increased HDL.

\section{ACKNOWLEDGMENTS}

We acknowledge those involved in the conduct of the study and thank the volunteers for their enthusiastic participation.

\section{REFERENCES}

Blanco-Molina A, Castro G, Martín-Escalante D, Bravo D, LópezMiranda J, Castro P, et al. (1998) Effects of different dietary cholesterol concentrations on lipoprotein plasma concentrations and on cholesterol efflux from Fu5AH cells. Am J Clin Nutr 68:1028-1033.

Bortnick AE, Rothblat GH, Stoudt G, Hoppe KL, Royer LJ, McNeish J, Francone O (2000) The correlation of ATP-binding cassette 1 mRNA levels with cholesterol efflux from various cell lines. J Biol Chem 275:28634-28640.

Castelli WP, Gordon T, Hjortland MC, Kagan A, Doyle JT, Hames CG, Hulley SB, Zukel WJ (1977) Alcohol and blood lipids. The Cooperative Lipoprotein Phenotyping Study. Lancet 2:153-155.

Channon KM, Clegg RJ, Bhatnagar D, Ishola M, Arrol S, Durrington PN (1990) Investigation of lipid transfer in human serum leading to the development of an isotopic method for the determination of endogenous cholesterol esterification and transfer. Atherosclerosis 80:217-226.

Colditz GA, Branch ALG, Lipnick RJ, Willett WC, Rosner B, Posner B, Hennekens CH (1985) Moderate alcohol and decreased cardiovascular mortality in an elderly cohort. Am Heart J 109:886-889.

Criqui MH, Cowan LD, Tyroler HA, Bangdiwala S, Heiss G, Wallace RB, Cohn R (1987) Lipoproteins as mediators for the effects of alcohol consumption and cigarette smoking in cardiovascular mortality: results from the Lipids Research Clinics Follow-up Study. Am J Epidemiol 126:629-637.

De La Llera Moya M, Atger V, Paul JL, Fournier N, Moatti N, Giral P, Friday KE, Rothblat G (1994) A cell culture system for screening human serum for ability to promote cellular cholesterol efflux. Arterioscler Thromb 14:1056-1065.

De Oliveira E Silva ER, Foster D, McGee Harper M, Seidman E, Smith JD, Breslow JL, Brinton EA (2000) Alcohol consumption raises HDL cholesterol levels by increasing the transport rate of apolipoproteins A-I and A-II. Circulation 102:2347-2352.

Dullaart RP, Riemens SC, Scheek LM, Van Tol A (1999) Insulin decreases plasma cholesteryl ester transfer but not cholesterol esterifica- 
tion in healthy subjects as well as in normoglyceridaemic patients with type 2 diabetes. Eur J Clin Invest 29:663-671.

Fielding CJ, Fielding PE (1995) Molecular physiology of reverse cholesterol transport. J Lipid Res 36:211-228.

Fournier N, Paul JL, Atger V, Cogny A, Soni T, De la Llera-Moya M, Rothblat GH, Moatti N (1997) HDL phospholipid content and composition as a major factor determining cholesterol efflux capacity from Fu5AH cells to human serum. Arterioscler Thromb Vasc Biol 17:26852691.

Glomset JA (1968) The plasma lecithins:cholesterol acyltransferase reaction. J Lipid Res 9:155-167.

Grobbee DE, Rimm EB, Keil U, Renaud S (1999) Alcohol and the cardiovascular system, in Health Issues Related to Alcohol Consumption (MacDonald EI ed), pp 125-179. Blackwell Science, Philadelphia.

Grootenhuis PA, Westenbrink S, Sie CMTL, Neeling ND, Kok FJ, Bouter LM (1995) A semiquantitative food frequency questionnaire for use in epidemiologic research among the elderly: validation by comparison with dietary history. J Clin Epidemiol 48:859-868.

Hendriks HFJ, Veenstra J, Van Tol A, Groener JEM, Schaafsma G (1998) Moderate doses of alcoholic beverages with dinner and postprandial high density lipoprotein composition. Alcohol Alcohol 33:403-410.

Ji Y, Jian B, Wang N, Sun Y, de la Llera Moya M, Phillips MC, Rothblat GH, Swaney JB, Tall A (1997) Scavenger receptor BI promotes high density lipoprotein mediated cellular cholesterol efflux. J Biol Chem 272:20982-20985.

Mertz DP, Thuilot G (1985) A micromethod for the determination of $\mathrm{HDL}_{2}$ and $\mathrm{HDL}_{3}$ cholesterol by precipitations with polyethylene glycol (in German). Arztl Lab 31:372-376.

Nishiwaki M, Ishikawa T, Ito T, Shige H, Tomiyasu K, Nakajima K, et al. (1994) Effects of alcohol on lipoprotein lipase, hepatic lipase, cholesteryl ester transfer protein, and lecithin:cholesterol acyltransferase in high-density lipoprotein cholesterol elevation. Atherosclerosis 111:99109.

Oram JF, Lawn RM, Garvin MR, Wade DP (2000) ABCA1 is the cAMPinducible apolipoprotein receptor that mediates cholesterol secretion from macrophages. J Biol Chem 275:34508-34511.

Ross R (1995) Cell biology of atherosclerosis. Annu Rev Physiol 57:791804.
Rothblat GH, De La Llera-Moya M, Atger V, Kellner-Weibel G, Williams DL, Phillips MC (1999) Cell cholesterol efflux: integration of old and new observations provides new insights. J Lipid Res 40:781-796.

Sakr SW, Senault C, Vacher S, Fournier N, Girard-Globa A (1996) Oleic acid-rich fats increase the capacity of postprandial serum to promote cholesterol efflux from Fu5AH cells. Biochim Biophys Acta 1300:49-55. Schuler-Lüttmann S, Zhu Y, Hoffmann M, März W, Feussner G, Wieland H, Assmann G, Von Eckardstein A (2000) Cholesterol efflux from normal and Tangier disease fibroblasts into normal, high-density lipoprotein-deficient, and apolipoprotein E-deficient plasmas. Metabolism 49:770-777.

Senault C, Betoulle D, Luc G, Hauw P, Rigaud D, Fumeron F (2000) Beneficial effects of a moderate consumption of red wine on cellular cholesterol efflux in young men. Nutr Metab Cardiovasc Dis 10:63-69.

Sierksma A, Van Der Gaag MS, Kluft C, Hendriks HFJ (2002) Moderate alcohol consumption reduces plasma C-reactive protein and fibrinogen levels; a randomized, diet-controlled intervention study. Eur J Clin Nutr 56:1130-1136.

Stampfer MJ, Colditz GA, Willett WC, Speizer FE, Hennekens CH (1988) A prospective study of moderate alcohol consumption and the risk of coronary disease and stroke in women. N Engl J Med 319:267-273.

Tall AR (1993) Plasma cholesteryl ester transfer protein. J Lipid Res 34:1255-1274.

Van der Gaag MS, Sierksma A, Schaafsma G, Van Tol A, GeelhoedMieras T, Bakker M, Hendriks HFJ (2000) Moderate alcohol consumption and changes in postprandial lipoproteins of premenopausal and postmenopausal women: a diet-controlled, randomized intervention study. J Womens Health Gend Based Med 9:607-616.

Van der Gaag MS, Van Tol A, Vermunt SHF, Scheek LM, Schaafsma G, Hendriks HFJ (2001) Moderate alcohol consumption stimulates early steps in reverse cholesterol transport. J Lipid Res 42:2077-2083.

Van Tol A, Groener JEM, Scheek LM, Van Gent T, Veenstra J, Van de Pol H, Hendriks HFJ, Schaafsma G (1995) Induction of net mass lipid transfer reactions in plasma by wine consumption with dinner. Eur J Clin Invest 25:390-395.

Widhalm K, Pakosta R (1991) Precipitation with polyethylene glycol and density-gradient ultracentrifugation compared for determining highdensity lipoprotein subclasses HDL2 and HDL3. Clin Chem 37:238240. 